\title{
Fatty acids composition in South African freshwater fish as indicators of food quality
}

\author{
Erasmus Chauke ${ }^{1}$, Ewa Cukrowska ${ }^{1}$, Mary-Jane Thaela-Chimuka², Luke Chimuka ${ }^{1 *}$, \\ Hermogene Nsengimana ${ }^{1}$ and Hlanganani Tutu ${ }^{1}$ \\ aSchool of Chemistry, University of the Witwatersrand, Private Bag 3, WITS 2050, Johannesburg, South Africa \\ ${ }^{b}$ Agricultural Research Council, Private Bag X2, Irene 0062, South Africa
}

\begin{abstract}
Lipid classes and fatty acid composition of three commercially important freshwater fish species Oreochromis mossambicus (Mozambique tilapia), Clarias gariepinus (African catfish) and Cyprinus carpio (carp) obtained from an aquaculture, different river systems and fish markets from different provinces in South Africa were investigated. Fatty acids were extracted from the fish fillets through the Folch extraction method (using chloroform: methanol at the ratio of 2:1). Generally, tilapia fish species was found to be the richest in fatty acid composition. In all fish species analysed, palmitic acid (16:0) was found to be the most abundant fatty acid ranging from 18.24 to $21.84 \%$. Appreciable quantities of essential polyunsaturated fatty acid such as docosahexaenoic (DHA) (22:6 n-3, 3.92 to 6.16\%), eicosapentaenoic acid (EPA) (20:5 n-3, 1.91 to 2.92\%) and arachidonic acid (20:4n-6, 7.19 to $8.50 \%)$ were also found. Observations show that fish species obtained from Gauteng Province are richer in fatty acids compared to those in Limpopo Province. The study points out that all fish species investigated contain appreciable levels of Omega-3 (n-3) polyunsaturated fatty acids (PUFA) and are therefore suitable for an unsaturated low-fat diet. This is important especially for poor communities who cannot afford to get a balanced diet, rich in some essential fatty acids.Therefore, it is important to determine the nutritional value of local fish, since it significantly contribute to a healthy diet in rural communities.
\end{abstract}

Keywords: fatty acid composition, lipids, freshwater fish, Omega -3 and Omega-6, polyunsaturated fatty acids, EPA, DHA

\section{Introduction}

Developments in chromatographic separation have led to a better understanding of the complexity of lipids from various origins (Brondz et al., 1983). Many studies have been dedicated to the effects of dietary fatty acid composition of fish lipids in connection with the essential fatty acids especially Omega-3 polyunsaturated fatty acids such as docosahexaenoic acid (DHA) and eicosapentaenoic acid (EPA) (Steffens, 1997). Both EPA and DHA cannot be synthesised in the human body and thus need to be supplemented through dietary intake (Gunstone, 1996). Several literature reports show that fish oil contains relatively high levels of polyunsaturated fatty acids (PUFA) in nature, with freshwater fish containing elevated levels of Omega-6, while marine fish arecharacterised by high concentration of Omega-3 (Gunstone, 1996; Steffens, 1997). These differences are linked to the lipid composition of the planktons they feed on (Gunstone, 1996; Gutierrez and Da Silva, 1993). There are a number of experiments demonstrating the effects of other factors such as environmental temperature, seasonal variations, age and species type on the fatty acid composition of aquatic animals especially fish (Rasoarahona et al., 2005). The general trend showing higher content of long chained PUFA at lower temperatures is quite clear, with the Omega-6/Omega-3 ratio decreasing with a decrease in temperature (Meed and Kayama, 1967; Rasoarahona et al., 2005; Schwalme et al., 1993).

\footnotetext{
* To whom all correspondence should be addressed.

单 +27 11717 6703; +27 72497 8041; fax: +27 11 717-6749;

e-mail: luke@chem.wits.ac.za or luke_chimuka@hotmail.com

Received 21 May 2007; accepted in revised form 29 November 2007.
}

Scientific studies have proven that consumption of fish containing elevated levels of Omega-3 PUFA especially DHA and EPA has positive effects on human health particularly in reducing the risk of attack by cardiovascular diseases and other related diseases such as atherosclerosis, thrombogenesis, high blood pressure, cancer, skin disease, etc. (Serhan et al., 2004; Connor, 2000; and Tapiero et al., 2002). These diseases and other related health problems are linked to an overproduction of eicosanoids and docosanoids which tend to affect the fluidity, flexibility and permeability of the cell membranes thus resulting in blood clotting in the nerves (British Nutrition Foundation, 1992; Connor, 2000; Kantogiannea et al., 2000). These findings have created a new market for fish oil as a food and dietary supplement to reduce the risk of attack by various diseases (Ackman, 1989).

Information on fatty acid composition of various freshwater and marine fish species originating from countries such as Hungary, the United States, Canada and Japan is available in the literature (Ackman, 1989) while little is available on the quality of South African fish in terms of their fatty acid composition.

This paper discusses the fatty acid composition of three commercially important freshwater fish species found in South Africa. The study aims to compare the levels of fatty acid composition in fish species from different freshwater ecosystems in South Africa. Fish quality in those ecosystems is important for rural communities since it contributes to a healthy diet.

\section{Materials and methods}

\section{Sample collection}

Different methods were used to collect fish samples for analysis. Some fish samples were randomly collected (purchased) from 
local suppliers at Thohoyandou (Limpopo Province) and around Johannesburg. Other samples were collected from various freshwater systems (Makuleke Dam in Limpopo; Loskop Dam in Mpumalanga and Vaal Dam in Gauteng Province). These regions were selected for sampling due to their differences in climatic conditions which influence the type of feeds available for fish and consequently their fatty acid composition. Other fish samples were obtained from an aquaculture system (Agricultural Research Council, Irene, South Africa). Fish samples were kept in an ice bath before being filleted, packed in vacuum bags and stored at below $-10^{\circ} \mathrm{C}$ as proposed by Christie (1993).

\section{Extraction of lipids}

From the whole fillet, tri-acylglycerols were extracted from 5 to $6 \mathrm{~g}$ of fish fillet through the use of the Folch extraction technique. This method involves mechanical homogenisation of the fatty tissue with 2:1 chloroform: methanol mixture to a final volume 20 times the volume of the tissue. To prevent autoxidation, $10 \mathrm{mg} / \ell$ of butylated hydroxytoluene was added to all samples. For complete recovery of fatty acids and isolation of non-fatty acids compounds, the extracts were repeatedly washed three times with $4 \mathrm{~m} \ell$ of $20 \mathrm{mg} / \ell$ sodium sulphate salt solution for each $20 \mathrm{~m} \ell$ of chloroform: methanol. The extracts were allowed to separate into layers, and the lower chloroform phase containing lipids was collected and evaporated under a nitrogen stream to preconcentrate the extracts before derivatisation.

\section{Preparation of methyl esters}

Before any gas chromatographic analysis, tri-acylglycerols (fatty acids) were converted into low-molecular weight non-polar derivatives by modifying their functional groups. This was done to improve volatility of the fatty acid compounds. Derivatisation was done according to the method explained by Christie (1993) acid-catalysed methanolysis, which involves hydrolysis of the lipid extract in $5 \mathrm{~m} \ell$ of $36 \% \mathrm{HCl}$ in $100 \mathrm{~m} \ell$ of methanol, sealed in test tubes and derivatised at $80^{\circ} \mathrm{C}$ for 5 to $6 \mathrm{~h}$. After cooling of the mixture, obtained fatty acid methyl esters (FAMEs) were finally extracted with $4 \mathrm{~m} \ell$ of petroleum ether and washed with $10 \mathrm{~m} \ell$ of de-ionised water.

\section{Gas-liquid chromatography}

Analysis of fatty acid methyl esters was performed on a HewlettPackard 5890A gas chromatographic technique equipped with a flame ionisation detector. A non-polar fused silica capillary column Omegawax-250 250 (30 m x $0.25 \mathrm{~mm}$ x $0.25 \mu \mathrm{m}$ film thickness) was used. For analysis, the operating conditions of the gas chromatographic technique were as follows: the column temperature was initially set at $80^{\circ} \mathrm{C}$ for $5 \mathrm{~min}$ and then increased to $150^{\circ} \mathrm{C}$ at the rate of $10^{\circ} \mathrm{C} \cdot \mathrm{min}^{-1}$ where it was held constant for $30 \mathrm{~min}$; the temperature was further increased to $220^{\circ} \mathrm{C}$ at $5^{\circ} \mathrm{C} \cdot \mathrm{min}^{-1}$ and finally held constant for another $30 \mathrm{~min}$. This was found to be the optimum temperature programming for the best separation and run time. Helium was used as a carrier gas, at a constant flow rate of $1 \mathrm{~m} \ell \cdot \mathrm{min}^{-1}$. The inlet (or injection port) and detector temperatures were kept at $250^{\circ} \mathrm{C}$. For analysis, the sample injection aliquot was $1 \mu \ell$. Other than carrier gas hydrogen and air were used as supportive gases.

\section{Qualitative determination}

Individual fatty acids were identified and quantified by compari-

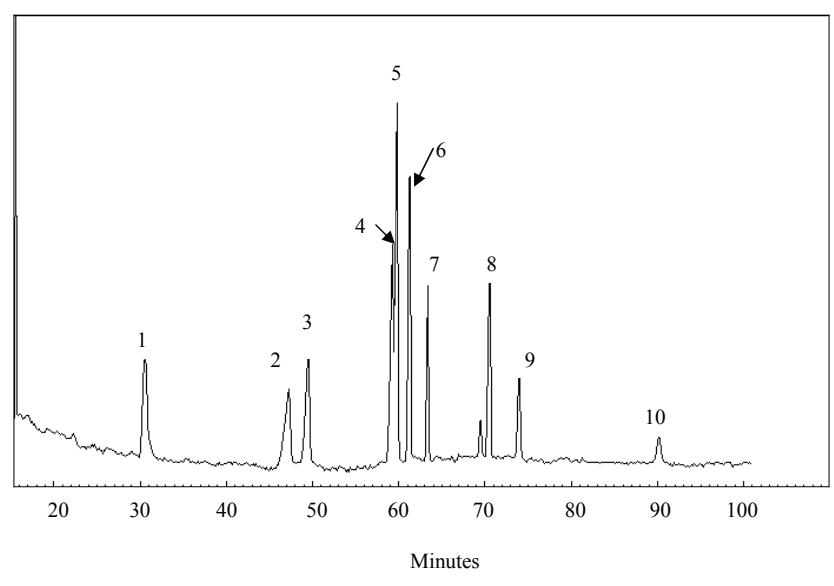

Figure 1

Chromatogram with 10 well-separated fatty acid standards. For names, see Fig. 2

son with retention times and peak areas of fatty acid methyl ester standards prepared and run under similar conditions as those of the real samples. Reagents used were of analytical grade (AR). All solvents were used without further purification. The area percentage and weight $\left(\mathrm{mg} \cdot \mathrm{g}^{-1}\right)$ in oil) of each of the fatty acid methyl esters were computed according to the AOAC official method 963.22 (AOAC, 1984).

\section{Results and discussion}

\section{Optimisation of the separation method}

The initial step of the study was optimisation of the analytical method to improve separation and detection of fatty acid analytes. The extraction and derivatisation times were held constant, while the temperature programme, run time and column choice which would provide the best separation were investigated. Best separations (shown in Fig. 1) were obtained on a fused silica capillary column Omegawax- $250^{\mathrm{TM}}$ (Supelco, $30 \mathrm{~m}$ x $0.25 \mathrm{~mm}$ x $0.25 \mu \mathrm{m}$ film thickness). Under optimised conditions, lower detection limits were attained with good separation of FAME peaks. All peaks obtained were identified by analysis of individual FAME standards (see Figs. 1 and 2). Omegawax-250 ${ }^{\mathrm{TM}}$ is a special purpose column specifically designed for use in the separation of fatty acid methyl esters. This column is coated with a less polar stationary phase (polyglycol-based on carbowax) when compared to the other column used (Nukol), which is a general purpose column. These chromatographic traces lend support to Christie's view that Omegawax- $250^{\mathrm{TM}}$ is the best special purpose column, and has been recommended for use by Christie (1989). Other than the capillary column, Gutierrez and Da Silva (1993) used a stainless steel column, $2 \mathrm{~m}$ x 5 mm, packed with Chromosorb W coated with $18 \%$ (by wt) of diethylene glycol succinate to obtain good separation of fatty acids in 7 Brazilian fish species.

\section{Quality assurance}

\section{Reproducibility of the instrument and the analytical method}

To determine the repeatability of the instrument, three replicate injections of the same $50 \mathrm{mg} \cdot \ell^{-1}$ standard mixture of fatty acid methyl esters were conducted. This was done to find out 


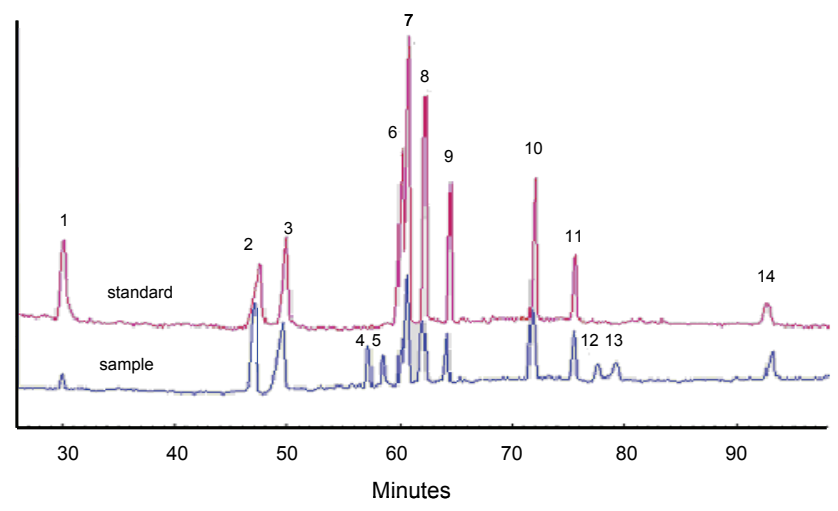

Figure 2

An overlay of FAME standards and fish sample chromatograms indicating identified fatty acids from the lipid matrix (NI = not identified). Key: $1=14: 0,2=16: 0,3=16: 1 n-7,4=\mathrm{NI}, 5=\mathrm{NI}$, $6=18: 0,7=18: 1 n-9,8=18: 2 n-6,9=18: 3 n-3,10=20: 4$ $n-6,11=20: 5 n-3,12=N I, 13=N I, 14=22: 6 n-3$

whether there would be any serious deviation or variations in retention times and peak areas of different compounds. The $\%$ RSD ranged between 3 to $14 \%$ proving good reproducibility of the gas chromatographic procedure.

The precision of the method was determined by conducting three replicate injections of three samples taken from the same portion of the same fish, extracted, derivatised and analysed under similar conditions. The mean peak area and percentage relative standard deviations (\% RSDs) were determined for each analyte. From the results shown in Table 1, it is evident that the method has good repeatability. There is a relatively low variation in the peak area with low relative standard deviations except for linolenic acid (18:3 n-3). The reproducibility of the retention times and area of the peaks made good identification of the fatty acids of interest; this was further compared with available literature data on the same fatty acids compounds. The results show that extraction, derivatisation and analysis methods used are precise and reproducible. The \% RSD ranged from 4 to $15 \%$ except for linoleic acid (18:3 n-3) where an RSD value of $29 \%$ was obtained.

\section{TABLE 1}

Mean peak area and relative standard deviations of different fatty acids obtained from three replicate injections of each of the three fish specimens extracted from the same fish

\begin{tabular}{|l|c|c|c|c|}
\hline & \multicolumn{3}{|c|}{ Fish sample } & \\
\hline Fatty acid & Part 1 & Part 2 & Part 3 & $\begin{array}{c}\text { Mean } \\
\text { 士 \% RSD }\end{array}$ \\
\hline $\mathbf{1 4 : 0}$ & 20.3154 & 18.7091 & 16.6045 & $18.543 \pm 10$ \\
\hline $\mathbf{1 6 : 0}$ & 120.6342 & 125.0995 & 131.0817 & $125.61 \pm 4$ \\
\hline $\mathbf{1 6 : 1}$ n-7 & 15.1163 & 11.3654 & 13.309 & $13.264 \pm 14$ \\
\hline $\mathbf{1 8 : 0}$ & 26.1281 & 22.0771 & 20.1069 & $22.77 \pm 14$ \\
\hline $\mathbf{1 8 : 1}$ n-9 & 61.3017 & 58.0752 & 45.9806 & $55.12 \pm 15$ \\
\hline $\mathbf{1 8 : 2}$ n-6 & 118.2043 & 112.4844 & 101.9598 & $110.55 \pm 7$ \\
\hline $\mathbf{1 8 : 3}$ n-3 & 31.0146 & 29.8217 & 26.8381 & $25.98 \pm 29$ \\
\hline $\mathbf{2 0 : 4}$ n-6 & 19.9166 & 23.4801 & 17.0764 & $20.16 \pm 15$ \\
\hline $\mathbf{2 0 : 5}$ n-3 & 15.5791 & 17.0165 & 17.8144 & $16.803 \pm 7$ \\
\hline $\mathbf{2 2 : 6}$ n-3 & 46.0113 & 43.9039 & 37.5267 & $42.481 \pm 10$ \\
\hline
\end{tabular}

\section{External calibration}

Fatty acid methyl esters found in the fish were identified by comparing their retention times with those of commercially available individual purified standards. Both standards and the real fish lipids extracts were analysed under the same operating conditions.

Figure 2 shows different FAMEs separated and identified from the fish sample. All fatty acids of interest were found to be present in all three South African fish species under study. From Fig. 2, stearic acid (18:0) was found to co-elute with oleic acid (18:1 n-9) and this may have caused quantification of these two fatty acids to be rather inaccurate. Pharmaceutically important fatty acids such as docosahexaenoic, ecosapentaenoic and arachidonic acid were also identified. From the sample matrix, other additional unknown peaks were obtained, which could be fatty acids too. However, further studies would be required to ascertain this, for instance using GC-MS or LC-MS/MS based techniques. This method has also been used by other researchers for identification of fatty acids from both freshwater and marine fish species (Gutierrez and da Silva, 1993; Erfanullah, 1998).

\section{Spiking}

Although all fatty acids of interest were identified through external calibration, identification was further confirmed by spiking fatty acid methyl esters (FAMEs) prepared from the fish extracts with $25 \mathrm{mg} \cdot \ell^{-1}$ of commercially available pure fatty acid standards.

Table 2 shows the area percentage of different FAMEs before and after $25 \mathrm{mg} \cdot \ell^{-1}$ fatty acid standard mixture was spiked. The results have shown an increase in area percentage of fatty acids of interest, while the area percentage of non-spiked compounds remained constant (data not shown). This therefore confirms availability of fatty acids identified through external calibration and retention times. Spiking of fatty acids is critical for identification of fatty acids since some non-fatty acid contaminants can behave like FAMEs. For identification, this method has reportedly been used especially for low concentrations of minor fatty acids and confusing unknown peaks. For identification of conjugated linoleic and linolenic acids as components of freshwater fish lipids, Medez et al. (1996) and Manning et al. (2006) used spiking of minor fatty acids for identification from other unknown sample peaks.

\section{TABLE 2}

Fatty acids from different fish species before and after spiking in peak areas

\begin{tabular}{|l|c|c|c|c|}
\hline \multirow{2}{*}{ Fatty acid } & \multicolumn{2}{|c|}{ Carp } & \multicolumn{2}{c|}{ Tilapia } \\
\cline { 2 - 5 } & Before & After & Before & After \\
\hline $\mathbf{1 4 : 0}$ & 3.6051 & 8.2140 & 7.338 & 11.946 \\
\hline $\mathbf{1 6 : 0}$ & 26.6925 & 32.5534 & 38.4944 & 46.0321 \\
\hline $\mathbf{1 6 : 1}$ n-7 & 14.7412 & 18.9322 & 8.6753 & 13.5564 \\
\hline $\mathbf{1 8 : 0}$ & 5.1956 & 11.7075 & 20.285 & 26.721 \\
\hline $\mathbf{1 8 : 1}$ n-9 & 17.9582 & 24.6318 & 34.0589 & 39.489 \\
\hline $\mathbf{1 8 : 2}$ n-6 & 18.8392 & 26.1491 & 20.3675 & 28.6110 \\
\hline $\mathbf{1 8 : 3}$ n-3 & 5.1153 & 9.8256 & 12.3675 & 15.8083 \\
\hline $\mathbf{2 0 : 4}$ n-6 & 6.9124 & 10.0983 & 9.0472 & 15.025 \\
\hline $\mathbf{2 0 : 5}$ n-3 & 4.0299 & 8.7107 & 4.5053 & 7.8339 \\
\hline $\mathbf{2 2 : 6}$ n-3 & 6.1727 & 9.4412 & 11.5759 & 15.9461 \\
\hline
\end{tabular}


TABLE 3

Fatty acid composition of freshwater fish from the three different selected sampling provinces in wt \%

\begin{tabular}{|l|c|c|c|c|c|c|c|}
\hline \multirow{2}{*}{ FAs } & \multicolumn{3}{|c|}{ Limpopo Province } & \multicolumn{3}{c|}{ Gauteng Province } & $\begin{array}{c}\text { Mpumalanga } \\
\text { Province }\end{array}$ \\
\cline { 2 - 8 } & Catfish & Carp & Tilapia & $\begin{array}{c}\text { Catfish } \\
\text { cultured }\end{array}$ & Carp & $\begin{array}{c}\text { Tilapia } \\
\text { cultured }\end{array}$ & Carp \\
\hline $\mathbf{1 4 : 0}$ & 2.32 & 1.06 & 3.52 & 3.57 & 2.92 & 4.13 & 1.84 \\
\hline $\mathbf{1 6 : 0}$ & 16.17 & 18.82 & 19.60 & 20.30 & 21.61 & 24.07 & 20.33 \\
\hline $\mathbf{1 6 : 1} \mathbf{n - 7}$ & 4.95 & 8.20 & 5.13 & 5.88 & 11.93 & 5.60 & 6.50 \\
\hline $\mathbf{1 8 : 0}$ & 3.19 & 3.39 & 4.37 & 4.11 & 3.89 & 5.09 & 4.72 \\
\hline $\mathbf{1 8 : 1} \mathbf{n - 9}$ & 11.80 & 10.61 & 16.09 & 18.43 & 14.54 & 21.98 & 12.16 \\
\hline $\mathbf{1 8 : 2} \mathbf{n - 6}$ & 13.43 & 17.47 & 14.81 & 10.04 & 15.25 & 13.14 & 15.29 \\
\hline $\mathbf{1 8 : 3} \mathbf{n}-3$ & 4.12 & 5.93 & 3.22 & 6.90 & 4.14 & 7.88 & 6.43 \\
\hline $\mathbf{2 0 : 4} \mathbf{n - 6}$ & 8.73 & 7.05 & 6.70 & 8.26 & 6.60 & 7.94 & 7.91 \\
\hline $\mathbf{2 0 : 5} \mathbf{n - 3}$ & 1.69 & 2.88 & 1.43 & 2.13 & 3.26 & 2.91 & 2.62 \\
\hline $\mathbf{2 2 : 6} \mathbf{n - 3}$ & 2.11 & 3.51 & 4.84 & 5.72 & 4.99 & 7.47 & 4.03 \\
\hline
\end{tabular}

\section{Detection limits}

From the fatty acids methyl ester's chromatograms, detection limits of all fatty acids of interest were calculated as the concentration corresponding to three times the noise level $(3 \sigma)$. From duplicate injections made, the average value was used.

The results obtained show that the sensitivity of the instrument was good. The lowest detection limit was about $2.5 \mathrm{mg} \cdot \ell^{-1}$ for oleic acid and $20 \mathrm{mg} \cdot \ell^{-1}$ for docosahexaenoic acid which is an essential fatty acid. The average detection limit was $9.7 \mathrm{mg} \cdot \ell^{-1}$. These detection limits were low enough for fatty acids of interest in all fish samples to be determined.

\section{Comparison by province of fatty acid composition in South African freshwater fish}

Table 3 indicates fatty acid composition of fish species collected from each province. For the Limpopo Province, the table shows that the concentration of fatty acids ranged between 1.43 and $19.60 \%$ for Oreochromis mossambicus (Mozambique tilapia), 1.06 to $18.82 \%$ for Cyprinus carpio (Carp) and 1.69 to $16.17 \%$ for Clarias gariepinus (catfish). Of all fatty acid groups, palmitic acid (16:0) was found to be the most dominant. Availability of high levels of palmitic acid supports the results obtained and published in many studies conducted on freshwater fish (Gutierrez and Da Silva, 1993; Christie, 1993; Rasoarahona et al., 2005). Higher levels of palmitic acid have been described as a characteristic of freshwater fish (Ackman, 1980). Important long-chain fatty acids such as docosahexaenoic (22:6), eicosapentaenoic (22:5) and arachidonic acid (22:4) were found in significant levels. Linoleic acid (18:2) was the most dominant polyunsaturated fatty acid, while linolenic acid (18:3) found to be the most abundant Omega-3 fatty acid. From a nutritional point of view, tilapia fish species are of better quality compared to the others since they are characterised by the highest level of important Omega-3 fatty acids such as eicosapentaenoic (EPA) and docosahexaenoic acid (DHA).

The saturated fatty acid percentages of the lipid extracted from the three fish species obtained from Gauteng ranged from 2.92 to $24.07 \%$. Polyunsaturated fatty acids ranged from 2.13 to $15.25 \%$. Of the saturated fatty acids, palmitic acid (16:0) has the greatest proportion than in any other fish analysed from other provinces. These results (high proportion of palmitic acid) are in agreement with the fatty acid composition of both tilapia and carp fish fillet reported by Csengeri and Farkas (1993). Oleic acid $(18: 1)$ is the main mono-unsaturated fatty acid in all the species analysed. Carp fish showed the lowest proportion of oleic acid $(14.45 \%)$ while tilapia had a higher proportion $(21.98 \%)$. This fatty acid has exogenous origin and usually reflects the type of diet of the fish (Ackman et al., 1980; Ackman, 1989).

Comparing Oreochromis mossambicus (tilapia) and Clarias gariepinus (catfish) which were both collected from an aquaculture system, tilapia fish species were found to have a higher content of TAGs than the catfish. Tilapia was found to consist of more docosahexaenoic acid which is the main essential fatty acid in lipid nutrition.

For Mpumalanga Province, the findings indicate that palmitic acid (16:0) is the most abundant fatty acid of all fatty acids obtained from the analysis. This is the case for the results obtained for other fish species from other provinces. Docosahexaenoic acid (22:6) was found to be more comparable in levels to the eicosapentaenoic acid (20:5). Due to high levels of long chain polyunsaturated fatty acids such as DHA and EPA, this type of fish can be used as nutritional supplement especially as a source of Omega-3 fatty acids.

Comparing fish from all provinces, the results in Table 3 show that fish species from the Gauteng Province (more specifically cultured) are characterised by high concentrations of TAGs. This could be attributed to the fish diet since these were cultured fish and were under a special diet. Gauteng's Oreochromis mossambicus species was found to have higher amounts of long-chain polyunsaturated fatty acids docosahexaenoic $(2.63 \%)$, eicosapentaenoic $(1.48 \%)$ compared to the same species from Limpopo Province.

From all fish species analysed, cultured fish have been shown to be of the best quality in terms of their fatty acid composition compared to other fish species obtained from the natural river systems. Although they have low levels of fatty acid composition compared to the ones from Gauteng, the results show that fish species from Mpumalanga and Limpopo Provinces still possess significant amounts of essential fatty acids which can be used as a diet supplement.

Table 4 provides data on fatty acid weight percentage composition of lipids of Clarias gariepinus (catfish), Cyprinus carpio (carp) and Oreochromis mossambicus (Mozambique tilapia). The fat content is influenced by species, geographical regions, age and diet (Piggott and Tucker, 1990). Of all fatty acids, palmitic (18.24 to $21.84 \%$ ) was found to be the most dominant of all fatty acid groups from all fish species under study, as has been pointed out by Gopakumar and Nair (1972) for Indian freshwater fish. All three fish species contained arachidonic acid (20:4), 


\begin{tabular}{|c|c|c|c|}
\hline \multicolumn{4}{|c|}{$\begin{array}{l}\text { TABLE } 4 \\
\text { Fatty acid composition of lipids of the three South } \\
\text { African freshwater fish species in wt } \%\end{array}$} \\
\hline \multirow[t]{2}{*}{ Fatty acids } & \multicolumn{3}{|c|}{$\begin{array}{l}\text { Fatty acids composition in South African } \\
\text { freshwater fish species (mean } \pm \text { RSD) }\end{array}$} \\
\hline & Catfish & Carp fish & Tilapia fish \\
\hline $14: 0$ & $2.95 \pm 0.3$ & $1.94 \pm 0.48$ & $3.83 \pm 0.11$ \\
\hline $16: 0$ & $18.24 \pm 0.16$ & $20.25 \pm 0.06$ & $21.84 \pm 0.15$ \\
\hline $16: 1 \mathrm{n}-7$ & $5.42 \pm 0.12$ & $8.88 \pm 0.31$ & $5.37 \pm 0.06$ \\
\hline 18:0 & $3.65 \pm 0.18$ & $4.0 \pm 0.17$ & $4.73 \pm 0.11$ \\
\hline 18:1 n-9 & $15.12 \pm 0.31$ & $12.44 \pm 0.16$ & $19.04 \pm 0.22$ \\
\hline 18:2 n-6 & $11.74 \pm 0.20$ & $16.0 \pm 0.08$ & $13.98 \pm 0.09$ \\
\hline 18:3 n-3 & $5.51 \pm 0.36$ & $5.50 \pm 0.22$ & $5.55 \pm 0.59$ \\
\hline $20: 4$ n-6 & $8.50 \pm 0.04$ & $7.19 \pm 0.09$ & $7.32 \pm 0.12$ \\
\hline $20: 5$ n-3 & $1.91 \pm 0.16$ & $2.92 \pm 0.11$ & $2.17 \pm 0.48$ \\
\hline 22:6 n-3 & $3.92 \pm 0.65$ & $4.18 \pm 0.18$ & $6.16 \pm 0.30$ \\
\hline
\end{tabular}

which is a precursor for prostaglandin and thromboxane biosynthesis (Pompeia et al., 2002). The level of arachidonic acid was high in all species with catfish consisting of the highest level $(8.50 \%)$. DHA and EPA have been shown to have preventive effects on human coronary artery disease (Leaf and Webber, 1988). Therefore, fish have been suggested as a key component for a healthy diet in humans (Leaf and Webber, 1988). Significant levels of EPA and DHA in fish species analysed indicate that this can be used to supplement essential fatty acids in the human diet. Comparing the three fish species, it can be seen that tilapia fish is the richest and has the highest composition of docosahexaenoic acid (22:6). In all fish analysed, this fatty acid was found in higher levels than eicosapentaenoic acid. These data confirmed earlier observations of Katikou et al. (2001) and Gunstone et al. (1978).

\section{Fatty acid composition (saturation levels) in South African freshwater fish}

Further analysis of the fatty acids was conducted. From this the quality of fatty acids in terms of their saturation was determined and computed. Figure 3 shows the total fatty acid composition of South African fish in terms of their level of saturation. Among unsaturated fatty acids, polyunsaturated fatty acids were found to be the most abundant. These data confirmed earlier observa-

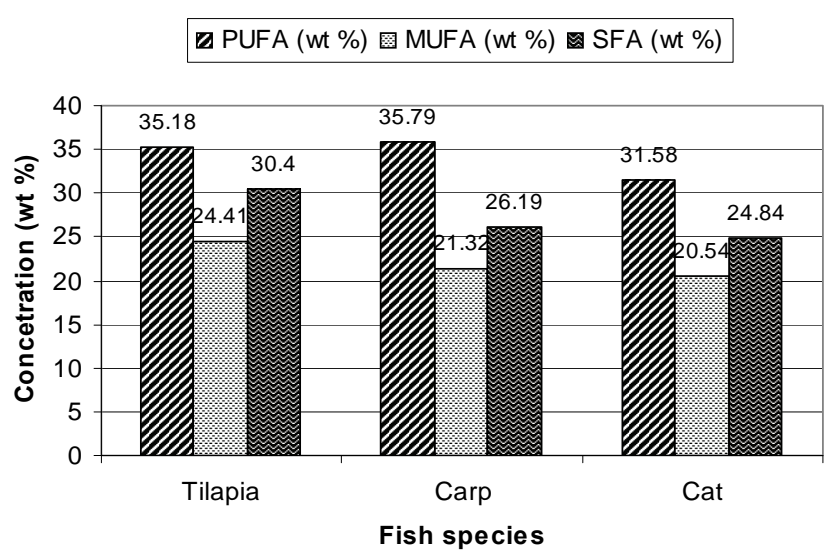

Figure 3

Fatty acid compositions on South African fish in terms of their level of saturation

tions of Ackman (1967); Dayhuff and Wells (2005); and Aras et al. (2003). In terms of the PUFAs, the study revealed that Cyprinus carpio is the richest of all fish containing about $35.79 \%$. The second highest was found to be in Oreochromis mossambicus with about $35.18 \%$ and $31.58 \%$ for Clarias gariepinus. High levels of PUFA compositions in South African fish are a clear indication that they are of good quality and can be used as nutritional supplement for human consumption. When compared to mono-unsaturated fatty acids, saturated fatty acids were found to be higher with tilapia having higher concentrations than other fish species.

\section{Omega-3 and Omega- 6 fatty acids composition}

The results shown in Table 5 indicate that all fish species analysed are characterised by high levels of Omega- 6 fatty acids. These results agree with those obtained in other studies conducted on freshwater fish species. Other studies show that freshwater fish are mainly characterised by elevated levels of Omega-6 polyunsaturated fatty acids especially linoleic (18:2) and arachidonic (22:4) acid (Ackman, 1967; Cowey and Sargent, 1972; Aras, 2003), as well as substantial concentrations of eicosapentaenoic and docosahexaenoic acid.

From the fish studied, Omega- 6 (n-6) fatty acids ranged from $23.19 \%$ for carp, $20.24 \%$ for catfish and $21.3 \%$ for tilapia fish

\begin{tabular}{|c|c|c|c|c|c|}
\hline \multicolumn{6}{|c|}{$\begin{array}{c}\text { TABLE } 5 \\
\begin{array}{c}\text { Comparison of fatty acids compositions between South African fish and } \\
\text { fish species from other countries }\end{array}\end{array}$} \\
\hline \multirow[b]{2}{*}{$\begin{array}{l}\text { Types of } \\
\text { fatty acids }\end{array}$} & \multicolumn{5}{|c|}{ Wt \% of fatty acid composition } \\
\hline & $\begin{array}{c}\text { Mozambique } \\
\text { tilapia (SA) }\end{array}$ & $\begin{array}{l}\text { Carp fish } \\
\text { (SA) }\end{array}$ & $\begin{array}{l}\text { Catfish } \\
\text { (SA) }\end{array}$ & $\begin{array}{l}\text { Carp fish } \\
\text { (Hungary) }\end{array}$ & $\begin{array}{c}\text { Tilapia } \\
\text { rendalli } \\
\text { (Madagascar) }\end{array}$ \\
\hline $14: 0$ & 3.83 & 1.94 & 2.95 & 1.7 & 3.31 \\
\hline 16:0 & 21.84 & 20.25 & 18.24 & 12.9 & 19.9 \\
\hline 16:1 n-7 & 5.37 & 8.88 & 5.42 & 7.3 & 9.14 \\
\hline 18:0 & 4.73 & 4.0 & 3.65 & 5.1 & 6.91 \\
\hline 18:1 n-9 & 19.04 & 12.44 & 15.12 & 14.8 & 13.2 \\
\hline $18: 2 \mathrm{n}-6$ & 13.98 & 16.0 & 11.74 & 7.9 & 5.05 \\
\hline $18: 3 \mathrm{n}-3$ & 5.55 & 5.50 & 5.51 & 2.9 & 0.46 \\
\hline $20: 4$ n-6 & 7.32 & 7.19 & 8.50 & 8.6 & 5.19 \\
\hline $20: 5 n-3$ & 2.17 & 2.92 & 1.91 & 8.8 & 2.52 \\
\hline $22: 6 n-3$ & 6.16 & 4.18 & 3.92 & 6.5 & 7.64 \\
\hline Total TAGs & 89.99 & 83.3 & 76.96 & 76.5 & 73.46 \\
\hline
\end{tabular}




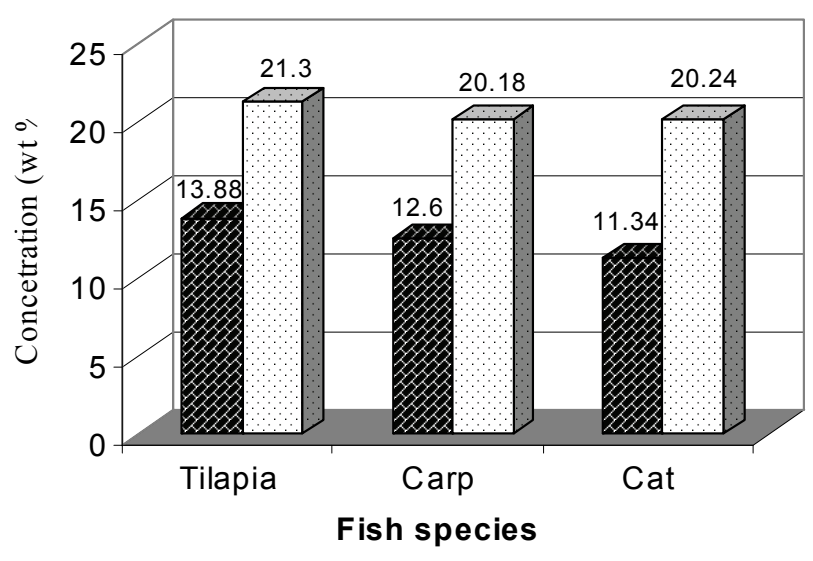

Omega-3 Omega-6

Figure 4

Representation of Omega-3 and Omega-6 fatty acids (wt \%) composition on different South African freshwater fish

species. These results show no greater difference in the level of Omega-6 polyunsaturated fatty acids characterising such South African freshwater fish species. The Omega-3/Omega-6 ratio has been suggested to be a useful indicator for comparing the relative nutritional value of fish oils. It was suggested that the ratio of 1:1-1:5 would constitute a healthy human diet (Osman et al., 2001). When compared to Omega-6 fatty acids, all fish species analysed were found to be characterised by low levels of Omega3 fatty acids. Because of the low content of Omega-3 fatty acids in freshwater fish, the ratio of total Omega-3 (n-3) to Omega-6 (n-6) fatty acids (essential fatty acid ratio) is much lower. All three fish species had the Omega-3/Omega- 6 ratio within the recommended ratio as suggested by Osman et al. (2001). Based on this, previous studies indicate that this is an opposite case for marine fish species which are mainly composed of Omega-3 and low levels of Omega-6 fatty acids (Steffens, 1997). Catfish was found to be composed of the lowest amount of $n-3$ fatty acids compared to carp and tilapia fish species. Tilapia fish was found to be the richest in n-3 fatty acids. Although they are highly characterised by $n-6$ fatty acids, this fish species can also serve as a valuable source of essential n-3 fatty acids especially EPA and DHA.

\section{Comparison of fatty acid composition in South African fish with those from other countries}

South African freshwater fish have shown higher concentrations of saturated, mono-unsaturated and polyunsaturated fatty acids. This suggests that they are of good quality. To support this, they are characterised by high levels of polyunsaturated fatty acids. Their high proportions of essential n-3 fatty acids such as EPA and DHA acid makes them to be a better source of essential fatty acids which are of greater pharmaceutical (or medicinal) importance since they are linked to reduced risk of cancer (Brondz, 2002; Steffens, 1997).

Other studies on similar fish species were conducted in other countries. Observations have shown that all similar species analysed are of higher quality (Table 5). These fish species were found to be characterised by high levels of essential fatty acids such as DHA and EPA. The high levels of palmitic and oleic acid in two South African freshwater fish species have been found to be comparable with those for the Hungarian carp and
Madagascan tilapia (freshwater fish) by Csengeri and Farkas (1993). Higher proportions of palmitic fatty acids in both South African fish and fish from other countries are an indication of their source of origin which is a characteristic for freshwater fish (Gutierrez and Da Silva, 1993; Rasoarahona et al., 2005).

Of all saturated fatty acids, palmitic fatty acid was found to be the highest. There is a minimal difference between Mozambican tilapia and Madagascan tilapia in terms of their palmitic fatty acid composition, with the former containing $1.94 \mathrm{wt} \%$ higher than the latter. Hungarian carp was found to contain 7.35 wt \% higher than the South African carp. In all fish species, oleic acid was found to be the most abundant mono-unsaturated fatty acid with South African fish containing levels higher than fish from other countries. The fatty acid profile of the analysed fish species generally fits into the typical pattern for freshwater fish where palmitic and oleic fatty acids are usually the major constituents.

Arachidonic acid (20:6n-6) was found in significant amounts in all species analysed. This is also the case in findings obtained in other studies on similar fish species from other geographical locations (Osman et al., 2001). Hungarian carp was found to be the richest fish in terms of the level of arachidonic concentration (8.6\%), while Tilapia rendalli consisted of the lowest level (5.19). Long-chained Omega-6 polyunsaturated fatty acids such as EPA and DHA were discovered in all fish. These types of fatty acids are used as indicators of fish quality (Osman et al., 2001). When compared to fish species from other countries, South African fish were found to contain low levels of essential fatty acids, especially DHA (22:5 n-3) and EPA (20:5 n-3). Hungarian carp have been shown to be the richest fish in terms of the level of eicosapentaenoic fatty acid composition; other findings show that it consists of $8.8 \mathrm{wt} \%$ with $5.88 \mathrm{wt} \%$ higher than that of the South African carp (2.92\%). The EPA levels obtained from the lipids of the Mozambican tilapia agree with the findings for the Madagascan tilapia, Tilapia rendalli.

The results obtained showed a considerable amount of polyunsaturated fatty acids in freshwater lipid fractions. Although not typical, the results obtained in the study are in agreement with many other published results on fatty acid contents in different fish species originating from different locations in the world (Csengeri and Farkas, 1993; Varljen et al., 2003). Generally, the fatty acid composition of the Mozambican tilapia, Tilapia rendalli, the South African carp and Hungarian carp show similar patterns, although Hungarian carp showed a significant fatty acid composition containing more polyunsaturated fatty acids. When compared to findings on studies conducted in some other countries (Hungarian carp and Madagascan tilapia), South African fish were found to be consisting of high total tri-acylglycerol levels, with Mozambique tilapia consisting of $89.99 \%$, followed by carp fish with $83.3 \%$ and catfish with $76.96 \%$. South African carp consisted of $6.8 \%$ higher than Hungarian carp fish (76.5\%), while Mozambique tilapia consisted of $16.53 \%$ higher than the Madagascan Tilapia rendali (73.43\%).

\section{Conclusion}

The fish oil isolated from three different fish species provided interesting data regarding the fatty acid composition of the total lipid classes. In all fish species analysed, different fatty acid groups (saturated, monounsaturated and polyunsaturated) were identified. Palmitic fatty acid was found to be the most abundant fatty acid with the highest concentration levels in all fish species. This is a common characteristic for freshwater fish. Essential fatty acids (medicinally important) such as eicosapen- 
taenoic (EPA) and docosahexaenoic (DHA) were identified and were found to be at higher/significant concentrations. Although there is a small variation, when compared to other species, tilapia was found to be the richest fish with higher concentrations of many essential fatty acids especially those which are essential for human nutrition. From the data obtained, higher proportions of Omega-6 PUFA were observed. Although they are mainly characterised by Omega- 6 fatty acids, these fish species can also serve as a valuable source of essential Omega-3 fatty acids especially docosahexaenoic and eicosapentaenoic acids. The distribution of fatty acids composition was found to be in accordance with observations in similar fish species from Hungary and Madagascar. In summary, all freshwater fish analysed are good sources of essential polyunsaturated fatty acids. Because of this, they can be used as an important source of essential polyunsaturated fatty acid (Omega-3).

\section{References}

ACKMAN RG (1989) Fatty acids. In: RG Ackman (ed.) Marine Biogenic Lipids, Fats and Oils. CRC Press, Boca Raton, 145-178.

ACKMAN RG (1980) Fish lipids. Part 1. In: JJ Connell (ed.) Advances in Fish Sciences and Technology. Fishing News Books. Ltd. Farnham, Surrey. 86-103.

ACKMAN RG (1967) Characteristics of the fatty acid composition and biochemistry of some fresh-water fish oils and lipids in comparison with the marine oils and lipids. Comp. Biochem. Physiol. 22 907-922.

ARAS NM, HALILOĞLU HI, YETIM H and AYIK Ö (2003) Comparison of fatty acid profiles of different tissues of mature trout (Salmo trutta labrax, Pallas, 1811) Caught from Kazandere Creek in the Oruh Region, Erzurum, Turkey. Turk J. Vet. Anim. Sci. 27 311-316.

BRITISH NUTRITION FOUNDATION (1992) Unsaturated Fatty Acids: Nutritional and Physiological Significance. Chapman and Hall, London, U.K.

BRONDZ I (2002) Development of fatty acid analysis by high-performance liquid chromatography, gas chromatography and related techniques. Anal. Chim. Acta 465 1-37.

BRONDZ I, OLSEN M and GREIBROK T (1983) Lipids separation and analysis. Chromatog. A 274299.

CHRISTIE WW (1989) Gas Chromatography and Lipids. Oily Press, Bridgwater. U.K.

CHRISTIE WW (1993) Preparation of ester derivative of fatty acids for chromatographic analysis. In: WW Christie (ed.) Advances in Lipid Methodology. Oily Press, Dundee. 2 69-111.

CONNOR WE (2000) Importance of n-3 fatty acids in health and disease. Am. Clin. Nutr. 71 1715-1755.

COWEY CB and SARGENT JR (1972) Lipid nutrition in fish. Comp. Biochem._Physiol. 57 269-273.

CSENGERI I and FARKAS T (1993) Effects of essential fatty acid deficient diets on the carcass acids and membrane viscosity in the common carp. Proc. EIFAC Workshop on Methodology for Determination of Nutrient Requirements in Fish. July 1993, Eichenau, Hungary.

DAYHUFF L and WELLS MJM (2005) Identification of fatty acids from fishes collected from Ohio River using gas chromatographymass spectrometry in chemical ionization and electron impact modes. Chromatog. A 1098 144-149.
ERFANULLAH AKJ (1998) Effect of dietary carbohydrate-to-lipid ratio on growth and body composition of walking catfish (Clarias batrachus). Aquacult. 161 159-168.

GOPAKUMAR K and NAIR MR (1972) Fatty acid composition of eight species of Indian marine fish. Sci. Food Agricult. Essex 23 493-496.

GUNSTONE F (1996) Fatty Acid and Lipid Chemistry. Blackie Academics and Professional. London, U.K.

GUNSTONE FD, WIJESUNDERA RC and SCRIMGEOUR CM (1978) The component acids of lipids from marine and freshwater species with special reference to furan-containing acids. Sci. Food Agricult. Essex 29 539-550.

GUTIERREZ LE and DA SILVA RCM (1993) Fatty acid composition of commercially important fish from Brazil. Sci. Agricult. Piracicaba 50 478-483.

KATIKOU P, HUGHES SI and ROBB DHF (2001) Lipid distribution within Atlantic salmon (Salmo salar) fillets. Aquacult. 202 89-99.

KONTOGIANNEA M, GUPTA and NTANIOS F (2000) Omega-3 fatty acids decrease endothelial adhesion of human colorectal carcinoma cells. Sur. Resourc. 92 201-205.

LEAF A and WEBBER PC (1988) Cardiovascular effects of n-3 fatty acids. New Eng. J. Med. 318 549-555.

MANNING BB, MENGHE HL, ROBINSON EH and PETERSON BC (2006) Enrichment of channel catfish (Ictalurus punctatus) fillets with conjugated linoleic acid and Omega-3 fatty acids by dietary manipulation. Aquacult. 261 337-342.

MEED JF and KAYAMA M(1967) Lipid metabolism in fish. In: ME Stansby (ed.) Fish Oils. Avi Publ. Co., Westport, Conn. 289-299.

MENDEZ E, GONZALEZ RM, GUSTAVO I, GLUDICE H and GROMPONEMA (1996) Lipid content and fatty acid composition of fillets of six fishes from the Rio de la Plata. Food Comp. Anal. 9 163-170.

OSMAN H, ZURRÍA AR and LAW EC (2001) Fatty acid composition and colesterol contento f selected marine fish in Malaysian waters. Food Chem. 73 55-60.

PIGGOT GM and TUCKER BW (1990) Effects of Technology on Nutrition. Marcel Dekker, New York, USA.

POMPEIA C, FREITAS JS, KIMJ S, ZYNGIER SB and CURI R (2002) Arachidonic acid cytotoxicity in leukocytes: Implications of oxidative stress and eicosanoid síntesis. Biol. Cell 94 (4) 251-265.

RASOARAHONA RE, BERNATHAN G, BIANCHINI JP and GAYDOU ME (2005) Influence of seasons on the lipid content and fatty acids profiles of three tilapia species, (Oreochromis niloticus, O. macrochir and Tilapia rendalli) from Madagascar. Food Chem. 91 (4) 683-694.

SCHWALME K, MACKAY WC and CLANDININ MT (1993) Seasonal dynamics of fatty acids composition in female northern pike (Esox Lucius). Comp. Physiol. 144 77-93.

SERHAN NC, GOTLINGER K, HONG S and ARITA M (2004) Resolvins, docosatrienes and neuroprotectins, novel Omega-3derived mediators, and their aspirin-triggered endogenous epimers: an overview of their protective roles in catabasis. Prostaglandins and Other Lipid Mediators 73 155-172.

STEFFENS W (1997) Effects of variation in essential fatty acids in fish feeds on nutritive value of freshwater fish for humans. Aquacult. 151 97-119.

TAPIERO H, NGUYEN BA, COUVREUR P and TEW KD (2002) Polyunsaturated fatty acids (PUFA) and eicosanoids in human health. Biomed. Pharmacother 56 215-222.

VARLJEN J, ŠULIC S, BRMALJ J, BATIČIĆ L, OBERSNEL V and KAPOVIĆ M (2003) Lipid classes and fatty acid composition of Diplodus vulgaris and Conger conger originating from Adriatic Sea. Food Technol. Biotechnol. 42 (2) 149-156. 
Available on website http://www.wrc.org.za ISSN 0378-4738 = Water SA Vol. 34 No. 1 January 2008

ISSN 1816-7950 = Water SA (on-line) 